\title{
Radiolabelled uterine proteins during early pregnancy and pseudopregnancy in mice after unilateral ovariectomy and superovulation
}

\author{
S. B. Fishel* \\ Marshall Laboratory, Physiological Laboratory, University of Cambridge, \\ Cambridge CB2 3EG, U.K.
}

\begin{abstract}
Summary. Uterine secretions were analysed after labelling in vivo with $\mathrm{L}-\left[4,5-{ }^{3} \mathrm{H}\right]$ leucine. The acid-precipitable counts were highest on Day 1 p.c., low on Day 2, lowest on Day 3, and similar to Day 2 values on Day 4 p.c. After unilateral ovariectomy the acid-precipitable counts for the horn $((+)$ ovary $)$ ipsilateral to the remaining ovary were higher than those in the contralateral horn ((-)ovary) for each condition studied. Superovulation yielded slightly higher acid-precipitable counts in the (-)ovary and (+)ovary horns of pregnant mice on Day 3 p.c., and in the $(+)$ ovary horn only for pseudopregnant mice on Day 2 p.c. The Day 2 counts for the $(+)$ ovary and $(-)$ ovary horns of the superovulating pseudopregnant mice were higher counts than those for superovulating pregnant mice, but the reverse occurred for (+)ovary horns only on Day 4 p.c. No qualitative differences between pseudopregnant and pregnant mice were observed on Day 4 and superovulation appeared to enhance the profiles obtained.
\end{abstract}

\section{Introduction}

Proteins present in the uterine lumen of mice have been closely examined in recent years (Gore-Langton \& Surani, 1976; Aitken, 1977a, b; Pratt, 1977; Fishel, 1979). During the first 4 days of pregnancy the protein profiles change dramatically and this reflects the changing ratio of progesterone and oestrogen secretions. These hormone-dependent changes in uterine proteins may play a role in the control of embryo metabolism and implantation (Surani, 1975; Aitken, 1977a; Pratt, 1977; Fishel, 1979). Fishel (1979) showed that particular groups of proteins that could be detected in the uterine lumen at implantation were not present when the milieu was unfavourable for implantation.

This investigation was carried out to observe uterine secretions during pregnancy and pseudopregnancy after unilateral ovariectomy and superovulation, in an attempt to detect changes which may be due to embryonic contribution or gonadotrophin treatment.

\section{Materials and Methods}

CFLP mice (Anglia Laboratories) were aged between 6 and 8 weeks and kept under standard animal house conditions with a lighting schedule of 05:00-19:00 h. Day 1 was the day of finding a vaginal plug.

Progesterone (4-pregnene-3,20-dione) and oestradiol benzoate (1,2,5(10)-oestratriene-3,13-

Present address: Animal Research Station, 307 Huntingdon Road, Cambridge CB3 0JQ, U.K. 
diol-3-benzoate) were obtained from Koch-Light Laboratories. L-[4,5- $\left.{ }^{3} \mathrm{H}\right]$ Leucine (sp. act. 53 $\mathrm{Ci} / \mathrm{mmol}$; Radiochemical Centre, Amersham) was used as the protein precursor. Anaesthesia was induced by tribromoethyl alcohol with amylene hydrate (Avertin: Winthrop Laboratories). PMSG (Folligon: Intervet, Cambs, England) and hCG (Chorulon: Intervet) were used for superovulation.

\section{Experiments}

Each animal was anaesthetized by an i.p. injection of tribromoethyl alcohol with amylene hydrate, using $0.2 \mathrm{ml}$ of a $1.2 \%$ solution per $\mathrm{g}$ body weight. In each animal the right ovary was located through a $0.7 \mathrm{~cm}$ dorsal incision and removed by cauterization of the oviduct. For convenience the uterine horns ipsilateral and contralateral to the remaining ovary are subsequently referred to as the (+)ovary and (-)ovary horns.

The animals were left undisturbed for a further $\mathbf{3 0}$ days, and the females were then placed with proven fertile males or with vasectomized males. Half of the pregnant and half of the pseudopregnant females were treated with 5 i.u. PMSG and 2.5 i.u. hCG $45 \mathrm{~h}$ later to induce superovulation. Ovulation number was increased up to 5 -fold in this strain of mouse. The numbers of animals used in the various groups are given in Table 1.

Radioactive labelling of proteins and collection and analysis of uterine secretions have been described previously (Fishel, 1979). Briefly, the mice were killed by cervical dislocation $6 \mathrm{~h}$ after the injection of radioactive leucine on Days $1,2,3$ or 4 p.c. The contents of the lumen were flushed from the oviductal end with $0.05 \mathrm{ml} 0.01 \mathrm{M}$-phosphate-buffered saline, $\mathrm{pH} 7.2$. After centrifugation, a buffer concentrate was added to the supernatant to give a final concentration of $0.1 \%$ sodium dodecyl sulphate, $0.14 \mathrm{M}-2$-mercaptoethanol and $10 \%$ glycerol. The samples were run on $6 \%$ SDS-polyacrylamide gels. After electrophoresis the gels were frozen using solid $\mathrm{CO}_{2}$ and sliced into $1 \mathrm{~mm}$ thick discs, using a gel slicer, before liquid scintillation spectrophotometry.

In a separate experiment, blastocysts were transferred to the (-)ovary horn of 6

Table 1. The amounts of labelled acid-precipitable proteins in the uteri of mice after unilateral ovariectomy and induction of superovulation

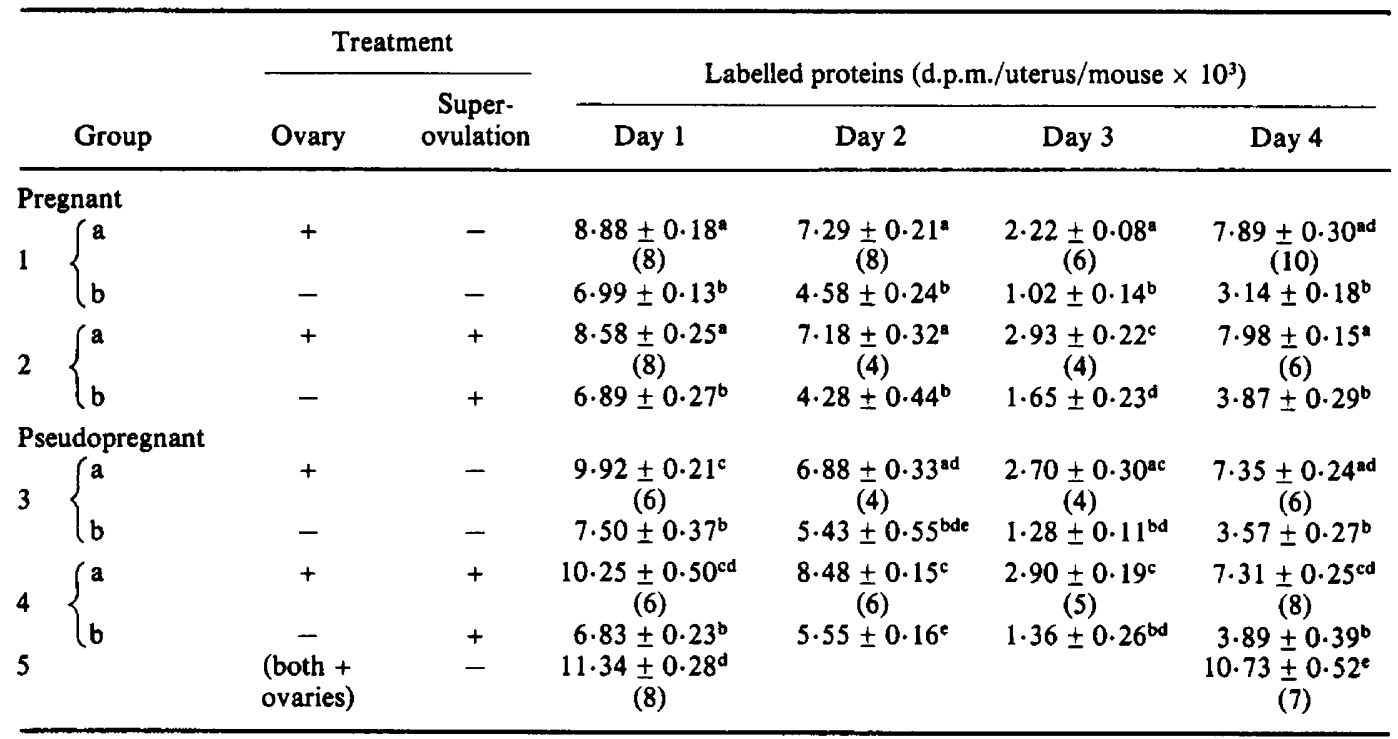

Values are mean \pm s.e.m. for the numbers of animals indicated in parentheses for each group.

Within columns, different superscripts indicate significant differences at at least $P<0.05$ (Student's $t$ test). 
pseudopregnant and 6 pregnant females. Half of the mice were killed on Day 19 p.c. and the rest allowed to go to term to determine whether the (-)ovary horn could support implantation and maintain pregnancy.

\section{Results}

Implantation occurred and pregnancy was maintained in the (-)ovary horn of pseudopregnant females. In pregnant mice, the remaining ovary supported pregnancy in the ipsilateral and contralateral horns. Parturition occurred normally at term.

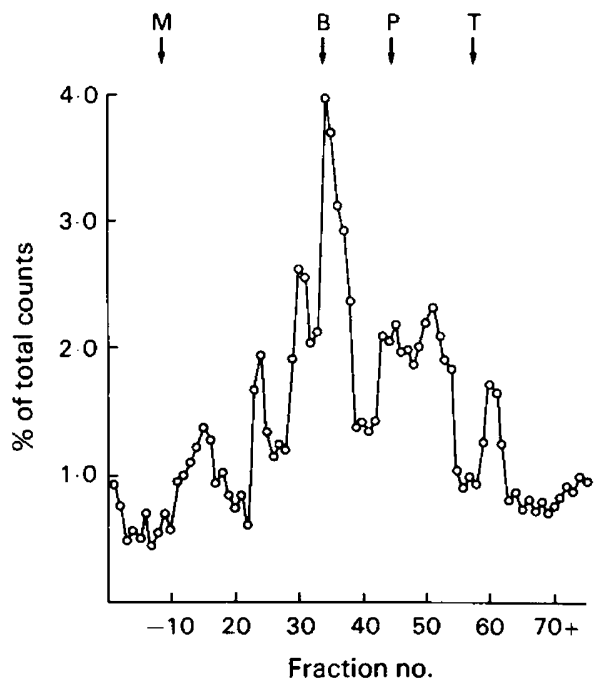

Text-fig. 1. Representative profile of radiolabelled proteins, analysed on 6\% SDS-polyacrylamide gels, in the uterine lumen of intact mice on Day 1 of pseudopregnancy (Group 5). $\mathbf{M}=$ myosin $; \mathbf{B}=$ bovine serum albumin; $\mathbf{P}=$ peroxidase $\mathbf{T}=$ trypsin.

As shown in Table 1 the counts of acid-precipitable radioactivity were highest on Day 1 p.c. and dropped to a nadir on Day 3 before rising again on Day 4 to a level similar to that on Day 2. In all conditions studied the (+)ovary horn had significantly higher counts than did the (-)ovary horn, except for Groups 3a and 3b on Day 2. For the electrophoretic gels the results, for 4-10 animals/group, were reproducible.

On Day 1 p.c. the values for pseudopregnant animals (Groups $3 \mathrm{a}$ and $4 \mathrm{a}$ ) were significantly higher than those of pregnant animals (Groups $1 \mathrm{a}$ and $2 \mathrm{a}$ ) for the (+)ovary horns. The qualitative profile observed on Day 1 p.c. for intact pregnant animals (Fishel, 1979) is very different from those analysed during pseudopregnancy (Text-fig. 1). In Group 5 there was a profile with 7 distinct peaks, but most of the radioactivity was incorporated into the protein with an approximate molecular weight of 64000 compared to that of 220000-260000 in pregnant animals.

On Day 2 p.c. the Group 4a horns yielded higher acid-precipitable counts than did those in Group 3a, but there was no detectable difference between Groups $3 \mathrm{~b}$ and $4 \mathrm{~b}$.

On Day 3 p.c. the values of Groups $1 \mathrm{a}$ and $1 \mathrm{~b}$ were significantly lower than those of Groups $2 a$ and $2 b$ respectively.

On Day 4 p.c. there was no detectable difference between values in Groups $3 \mathrm{a}$ and $4 \mathrm{a}$ and $3 \mathrm{~b}$ and $4 \mathrm{~b}$, but values in Group $2 \mathrm{a}$ were significantly higher than those in Group $4 \mathrm{a}$. The protein profiles obtained on Day 4 p.c. during the different experimental conditions are illustrated in 
Text-fig. 2. Apart from some minor differences the profiles are essentially very similar. Up to 9 peaks were detected and most of the radioactivity was always incorporated in the fraction corresponding to a molecular weight of 65000-68 000. In Group 1 (Text-fig. 2a) the protein with an approximate molecular weight of 30000 was not detected in the (-)ovary horn and the 13000-14000 molecular weight protein was not detected in the (+)ovary horn. The $13000-14000$ protein was also undetected in Group 3 (Text-fig. 2b). Superovulation appeared to enhance the definition of the profiles for pseudopregnant mice but not those of the pregnant animals.

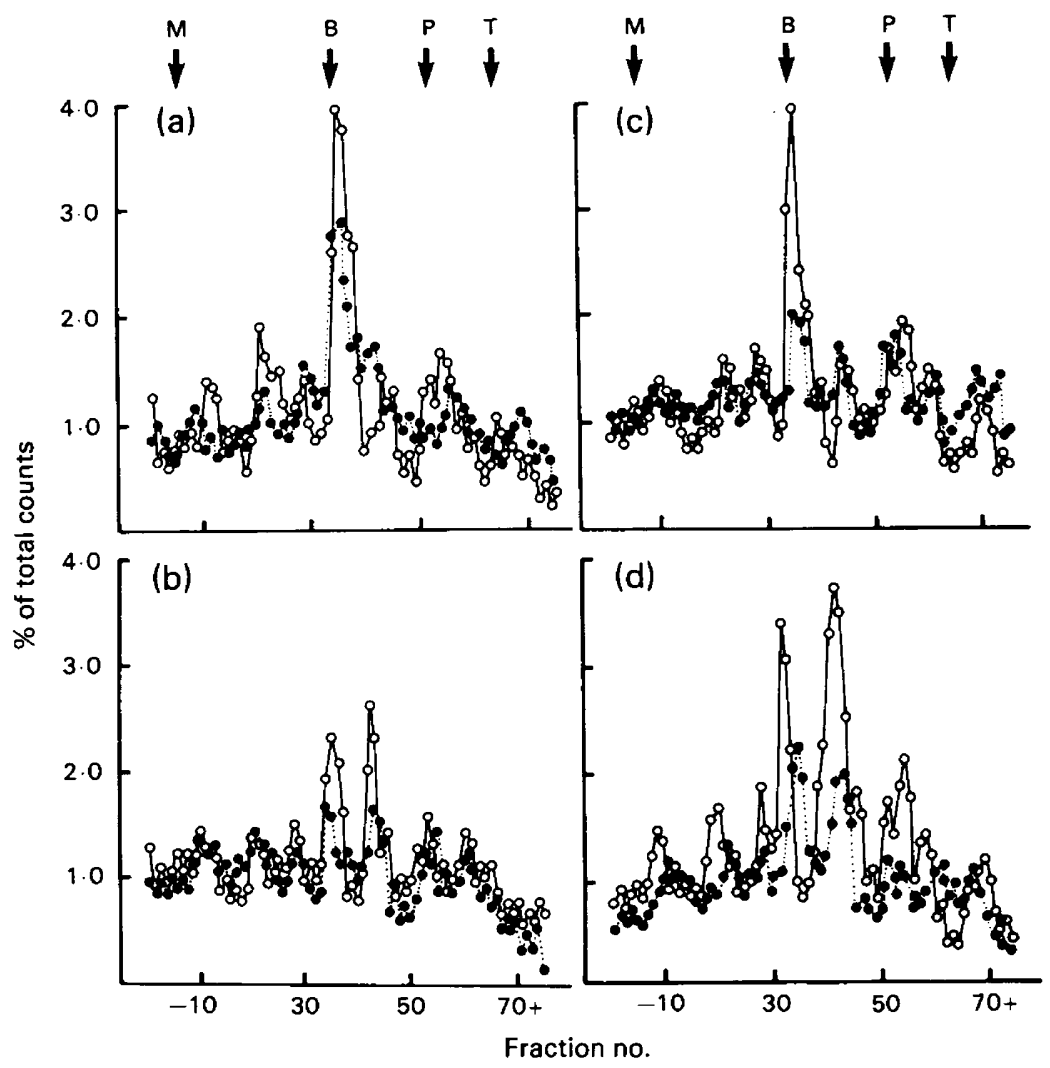

Text-fig. 2. Representative profiles of radiolabelled proteins, analysed on 6\% SDS-polyacrylamide gels, in the uterine lumen at day 4 p.c. of mice from (a) Group 1, (b) Group 3, (c) Group 2 and (d) Group 4 (see Table 1) according to the presence $(0)$ or absence $(0)$ of the ovary on that side. $M=$ myosin; $B=$ bovine serum albumin; $P=$ peroxidase; $T=$ trypsin.

\section{Discussion}

The previous study on radiolabelled uterine-secreted proteins (Fishel, 1979) during the first 4 days of pregnancy analysed only pregnant animals and used pooled samples. In this study radiolabelled uterine proteins were analysed during pseudopregnancy, after unilateral ovariectomy and also after superovulation. These treatments allow comparisons between the presence and absence of spermatozoa in the uterine lumen and any putative sperm products, changes due to increased gonadotrophins, any embryonic contribution, and variations in the endocrine states of particular animals. 
The results suggest that the various endocrine states have little effect on the profile of uterine proteins, labelled in vivo. On all 4 days the amount of acid-precipitable material in the uterine lumen was higher in the (+)ovary horns than in the (-)ovary horns, regardless of whether the females were pregnant or pseudopregnant or the numbers of eggs ovulated. These lower counts may have been caused by tissue damage inflicted during ovariectomy. However, the protein profiles in the (-)ovary horns were reproducible and the presence of the ovary would appear to have some influence on the proteins secreted into the uterine lumen.

The qualitative differences between pregnant and pseudopregnant animals on Day 1 p.c. may be an indication that certain products from spermatozoa are contributing to the uterine milieu, or that spermatozoa induce particular secretions from the uterus. The quantitative difference on Day 2 between pseudopregnant animals ovulating normally or induced to superovulate (Group 4) may be a truer representation of uterine-specific proteins than the results observed for pregnant animals (Group 2).

The induction of superovulation by circulating gonadotrophins did not qualitatively affect the profiles of uterine proteins during early pregnancy (results for Days 2 and 3 p.c., unpublished), in spite of the increased numbers of embryos. On Day 4 p.c. however, the induction of superovulation led to a slight, but significant, quantitative difference between the pregnant and pseudopregnant states, suggesting that the embryos may take-up and incorporate some of the injected label and release labelled protein into the milieu. Mouse blastocysts have been shown to synthesize and release glycoproteins into the medium in vitro (Fishel \& Surani, 1980). Although no embryonic contribution was detected in the protein profiles in the present study this does not preclude its presence; an embryonic contribution may have been masked by the uterine secretions. It is also possible that the presence of embryos induces an increase in uterine secretion (Nilsson, 1974).

As similar radiolabelled protein profiles were obtained in the presence or absence of embryos at the time of implantation it can be concluded that the changes detected on Day 4 p.c. are not a result of implantation and therefore not a marker for it. These results confirm earlier work (Aitken, 1977b). The results for the pseudopregnant females on Day 4 p.c., indicative solely of uterine-specific proteins, show an enhancement of profiles with superovulation (Group 4a compared with Group 3a) which has been reported previously (Gore-Langton \& Surani, 1976). The rise on Day 4, both quantitatively and qualitatively, of uterine-secreted proteins makes it difficult to regard them as having a passive role, and the possible biological functions of these macromolecules requires investigation. Tzartos \& Surani (1979) have used ${ }^{125}$ I-labelled uterine proteins to show that uterine proteins from Day 5 pregnant rats have a higher affinity for rat blastocysts than do uterine proteins from pro-oestrous animals or albumin. Such proteins may help to maintain optimal embryonic metabolism (Fishel \& Surani, 1978).

I thank Dr M. A. H. Surani for advice on the work and manuscript and Mrs A. Burling for experimental help. This work was supported by a Medical Research Council Studentship, and supported in part by a Ford Foundation Grant to Professor C. R. Austin and an M.R.C. Project Grant to Dr M. A. H. Surani. S.B.F. is a Beit Memorial Research Fellow.

\section{References}

Aitken, R.J. (1977a) Changes in the protein content of mouse uterine flushings during normal pregnancy and delayed implantation, and after ovariectomy and oestradiol administration. J. Reprod. Fert. 50, 29-36.

Aitken, R.J. (1977b) The protein content of mouse uterine flushings during pseudopregnancy. $J$. Reprod. Fert. 50, 191-192.
Fishel, S.B. \& Surani, M.A.H. (1978) Changes in the responsiveness of preimplantation mouse embryos to serum. J. Embryol. exp. Morph. 45, 295-301.

Fishel, S.B. (1979) Analysis of mouse uterine proteins at pro-oestrus, during early pregnancy and after administration of exogenous steroids. J. Reprod. Fert. 55, 91-100. 
Fishel, S.B. \& Surani, M.A.H. (1980) Evidence for the synthesis and release of a glycoprotein by mouse blastocysts. J. Reprod. Fert. 59, 181-185.

Gore-Langton, R.E. \& Surani, M.A.H. (1976) Uterine luminal proteins of mice. J. Reprod. Fert. 46, 271-274.

Nilsson, O. (1974) The morphology of blastocyst implantation. J. Reprod. Fert. 39, 187-194.

Pratt, H.P.M. (1977) Uterine proteins and the activation of embryos from mice during delayed implantation. J. Reprod. Fert. 50, 1-8.

Surani, M.A.H. (1975) Hormonal regulation of proteins in the uterine secretions of ovariectomized rats and the implication for implantation and embryonic diapause. J. Reprod. Fert. 43, 411-417.

Tzartos, S.J. \& Suranl, M.A.H. (1979) Affinity of uterine luminal proteins for rat blastocysts. J. Reprod. Fert. 56, 579-586.

Received 13 December 1979 